\title{
A novel $\mathrm{CoOOH} /(\mathrm{Ti}, \mathrm{C})-\mathrm{Fe}_{2} \mathrm{O}_{3}$ nanorod photoanode for photoelectrochemical water splitting
}

\author{
Kai-Hang $\mathrm{Ye}^{1,3 \dagger}$, Zilong Wang ${ }^{1 \dagger}$, Haibo $\mathrm{Li}^{3}$, Yufei Yuan ${ }^{1}$, Yongchao Huang ${ }^{2^{*}}$ and Wenjie Mai ${ }^{1^{*}}$
}

\begin{abstract}
In this work, we demonstrate the $\mathrm{CoOOH} /(\mathrm{Ti}$, $\mathrm{C})-\mathrm{Fe}_{2} \mathrm{O}_{3}$ (CTCF) nanorods prepared by a facile approach as well as their implementation as photoanodes for photoelectrochemical (PEC) water splitting. The photocurrent density of CTCF photoanode is $1.85 \mathrm{~mA} \mathrm{~cm}^{-2}$ at $+1.23 \mathrm{~V} v s$. reversible hydrogen electrode (RHE), which is more than 20 times higher than that of pristine $\alpha-\mathrm{Fe}_{2} \mathrm{O}_{3}$ photoanode $\left(0.08 \mathrm{~mA} \mathrm{~cm}{ }^{-2}\right)$. The incident-photo-to-current conversion efficiency, applied bias photo-to-current efficiency and transfer efficiency of CTCF photoanode reaches $31.2 \%$ at $380 \mathrm{~nm}(+1.23 \mathrm{~V}$ vs. RHE), $0.11 \%(+1.11 \mathrm{~V} v s$. RHE), $68.2 \%(+1.23 \mathrm{~V}$ vs. RHE) respectively, which are much higher than those of pristine $\alpha-\mathrm{Fe}_{2} \mathrm{O}_{3}$ photoanode. Additionally, the longtime irradiation PEC water splitting of CTCF photoanode demonstrates its high stability at extreme voltage in $\mathrm{NaOH}(\mathrm{pH} 14)$.
\end{abstract}

Keywords: photoelectrochemistry, water splitting, doping, ferric oxide

\section{INTRODUCTION}

Solar to hydrogen energy conversion is one of the most promising future energy forms to solve the energy shortage and environmental problems, due to its renewable, carbon-free, and environmentally friendly features [1-3]. Different from the photocatalysis of water splitting, photoelectrochemical cell (PEC) hydrogen production has some outstanding advantages, such as higher solar utilization, easier to recycle and faster hydrogen production rate $[1,4,5]$. The photoelectrodes are the key factors to the efficiency of PEC water splitting like the leaves of photosynthesis in the nature [4]. Many efforts have been devoted to exploring highly active photoanode materials such as $\mathrm{TiO}_{2}[6,7], \mathrm{ZnO}[8,9], \mathrm{Nb}_{2} \mathrm{O}_{5}$ [10], $\mathrm{BiVO}_{4}[11,12]$ and $\mathrm{WO}_{3}$ [13-15].

Hematite $\left(\alpha-\mathrm{Fe}_{2} \mathrm{O}_{3}\right)$ is one of the most promising earthabundant catalysts for photoanode, which can absorb a substantial portion of the solar spectrum $(300-600 \mathrm{~nm})$ [16-19]. This feature makes $\alpha-\mathrm{Fe}_{2} \mathrm{O}_{3}$ possess a remarkable maximum water oxidation photocurrent density $\left(J_{\max }\right)$ for solar water splitting [20]. However, some intrinsic features of $\alpha-\mathrm{Fe}_{2} \mathrm{O}_{3}$ in charge separation, electrical conductivity, material stability and surface oxygen evolution catalytic activity limit the PEC water splitting efficiency $[21,22]$.

The $J_{\max }$ of $\alpha-\mathrm{Fe}_{2} \mathrm{O}_{3}$ is more than $12 \mathrm{~mA} \mathrm{~cm}{ }^{-2}$, but the reported water oxidation photocurrent densities of $\alpha-\mathrm{Fe}_{2} \mathrm{O}_{3}$ are within the range of $1-5 \mathrm{~mA} \mathrm{~cm}^{-2}$ [20,23], due to the poor electrical conductivity $[3,16,24]$, which results in inefficient migration rate and poor separation of photo-generated electrons and holes [25], resulting in solar energy degradation $[22,23]$. We believe that future enhancement of the PEC performance of $a-\mathrm{Fe}_{2} \mathrm{O}_{3}$ photoanode will focus on improving the electrical conductivity of $\alpha-\mathrm{Fe}_{2} \mathrm{O}_{3}$.

Doping is an effective method to enhance the electrical conductivity of $\alpha-\mathrm{Fe}_{2} \mathrm{O}_{3}$-based photoanode for PEC water splitting [24]. For example, Li et al. [16] indicated that a novel $\mathrm{Sn}-\mathrm{Fe}_{2} \mathrm{O}_{3}$ photoanode achieved the excellent photocurrent density of $\sim 1.36 \mathrm{~mA} \mathrm{~cm}^{-2}$ at $0.23 \mathrm{~V}$ vs. Ag/ $\mathrm{AgCl}$. The Sn element doping can effectively enhance its electrical conductivity. Recently, two or more elements doping of photoanodes are also catching researchers'

${ }^{1}$ Siyuan Laboratory, Guangzhou Key Laboratory of Vacuum Coating Technologies and New Energy Materials, Department of Physics, Jinan University, Guangzhou 510632, China

${ }^{2}$ Key Laboratory for Water Quality and Conservation of the Pearl River Delta, Ministry of Education, School of Environmental Science and Engineering, Guangzhou University, Guangzhou 510006, China

${ }^{3}$ Fine Chemical Industry Research Institute, School of Chemical Engineering and Technology, Sun Yat-sen University, Guangzhou 510275, China

${ }^{\dagger}$ These authors contributed equally to this work.

* Corresponding authors (emails: wenjiemai@gmail.com (Mai W); huangych5@mail2.sysu.edu.cn (Huang Y)) 
wide attention [26]. Tang et al. [24] indicated that a novel $\mathrm{Fe}_{2} \mathrm{O}_{3}$ with $\mathrm{Ti}$, Sn and In doping photoanode achieved the excellent photocurrent density of $\sim 2.2 \mathrm{~mA} \mathrm{~cm}^{-2}$ at $+1.23 \mathrm{~V} v s . \mathrm{Ag} / \mathrm{AgCl}$.

On the other hand, when the photo-generated electrons and holes are separated from the inside of $\alpha-\mathrm{Fe}_{2} \mathrm{O}_{3}$, the photo-generated electrons will move to the cathode of PEC cell for hydrogen evolution reaction (HER) and the photo-generated hole will move to the surface of photoanode for oxygen evolution reaction (OER) $[1,23]$. However, the PEC water splitting performance of $\alpha-\mathrm{Fe}_{2} \mathrm{O}_{3}$ is limited because a majority of the holes are recombined when migrating to surface, leading to the poor catalytic activity of the $\alpha-\mathrm{Fe}_{2} \mathrm{O}_{3}$ surface for oxygen evolution [24]. Recently, $\mathrm{FeOOH}$ as an oxygen evolution catalyst (OEC) attracted great attention due to its excellent OER catalytic capacity [24]. Similar to $\mathrm{FeOOH}, \mathrm{CoOOH}$ is also an excellent OEC for electrical water splitting, but few studies were carried out on its application for PEC water splitting [27].

In this work, we utilize $\mathrm{C}$ and $\mathrm{Ti}$ doping $\mathrm{Fe}_{2} \mathrm{O}_{3}$ to increase its electrical conductivity, and $\mathrm{CoOOH}$ OEC layer to enhance its OER capacity as an OEC material. The obtained $\mathrm{CoOOH} /(\mathrm{Ti}, \mathrm{C})-\mathrm{Fe}_{2} \mathrm{O}_{3}$ photoanode achieves $1.85 \mathrm{~mA} \mathrm{~cm}^{-2}$ at $+1.23 \mathrm{~V}$ vs. RHE, which is more than 20 times higher than that of pristine $\alpha-\mathrm{Fe}_{2} \mathrm{O}_{3}$ photoanode $\left(0.08 \mathrm{~mA} \mathrm{~cm}^{-2}\right)$.

\section{EXPERIMENTAL SECTION}

\section{Synthesis of the catalysts}

The $\alpha-\mathrm{Fe}_{2} \mathrm{O}_{3}$ nanorod arrays were fabricated according to the literature [28]. $2.0 \mathrm{~g}$ ferric chloride $\left(\mathrm{FeCl}_{3} \cdot 6 \mathrm{H}_{2} \mathrm{O}\right)$ was dissolved into $50 \mathrm{~mL}$ deionized water, and sealed in a Teflon-liner. The fluorine doped tin oxide (FTO)-coated glass of $4 \mathrm{~cm} \times 5 \mathrm{~cm}$ was cleaned with deionized water, ethanol and acetone, and then placed in the liner with the FTO side facing the wall of the liner. The Teflon-liner was put into a self-sealing autoclave and heated at $100^{\circ} \mathrm{C}$ for $3 \mathrm{~h}$. After the reaction, the yellow films formed on the FTO substrates were thoroughly rinsed with deionized water and transferred to a furnace. Then the yellow films coated substrates were annealed at $550^{\circ} \mathrm{C}$ for $2 \mathrm{~h}$ and then at $750^{\circ} \mathrm{C}$ for $30 \mathrm{~min}$ with a ramp rate of $5^{\circ} \mathrm{C} \mathrm{min}^{-1}$ to obtain the $\alpha-\mathrm{Fe}_{2} \mathrm{O}_{3}$. The $\mathrm{Ti}-\mathrm{Fe}_{2} \mathrm{O}_{3}$ nanorod arrays were prepared by adding $10 \mu \mathrm{L} \mathrm{TiCl}_{3}$ into the $\mathrm{FeCl}_{3}$ aqueous solution. The $\mathrm{C}-\mathrm{Fe}_{2} \mathrm{O}_{3}$ nanorod arrays were obtained by adding $0.5 \mathrm{~g}$ glucose into the $\mathrm{FeCl}_{3}$ aqueous solution. The $(\mathrm{Ti}, \mathrm{C})-\mathrm{Fe}_{2} \mathrm{O}_{3}$ nanorod arrays were obtained by adding $0.5 \mathrm{~g}$ glucose and $10 \mu \mathrm{L} \mathrm{TiCl}$ into the $\mathrm{FeCl}_{3}$ aqueous solution. The ( $\mathrm{Ti}, \mathrm{C})-\mathrm{Fe}_{2} \mathrm{O}_{3}$ nanorod arrays was immersed in $0.01 \mathrm{~mol} \mathrm{~L}^{-1}$ cobalt acetate aqueous solution and polarized at $0 \mathrm{~V}$ vs. $\mathrm{Ag} / \mathrm{AgCl}$ in dark using $\mathrm{Pt}$ mesh as counter electrode. Then it was illuminated with a sun light simulator with incident light power controlled to be $100 \mathrm{~mW} \mathrm{~cm}{ }^{-2}$ and maintained for only $30 \mathrm{~s}$ to obtain the $\mathrm{CoOOH} /(\mathrm{Ti}, \mathrm{C})-\mathrm{Fe}_{2} \mathrm{O}_{3}$ nanorod arrays.

\section{Characterization}

All the catalysts were characterized by field emission scanning electron microscope (SEM, JSM-6330F), X-ray diffractometer (XRD, D8 ADVANCE), X-ray photoelectron spectroscope (XPS, ESCALab250), transmission electron microscope (TEM, JEM2010-HR), atomic force microscope (AFM, SPM-9500J3 microscope) and UV-vis spectrophotometer (UV-2450). The electrochemical testing was carried out with a CHI660C electrochemical station in a standard three electrode configuration.

\section{PEC measurements}

Photoelectrochemical measurements were performed with an electrochemical analyzer in a three-electrode configuration using the catalysts on FTO as the working electrode, Pt wire as the counter electrode, and an $\mathrm{Ag} /$ $\mathrm{AgCl}$ reference electrode. An aqueous solution of $1 \mathrm{~mol} \mathrm{~L}^{-1} \mathrm{NaOH}$ was used as electrolyte ( $\left.\mathrm{pH} 14\right)$. The working electrodes were immersed into the electrolyte and $1 \mathrm{~cm}^{2}$ surface areas exposed. The illumination source was AM 1.5G solar simulator (Newport, LCS 100 94011A (class A, Fig. S1)) directed at the quartz PEC cell $\left(100 \mathrm{~mW} \mathrm{~cm}^{-2}\right)$. Monochromatic incident photon-toelectron conversion efficiency (IPCE) were collected by a Solartron 1280B electrochemical station with a solar simulator (Newport 69920, $1000 \mathrm{~W}$ xenon lamp), coupled with an infrared water filter (Oriel 6127) and aligned monochromator (Oriel Cornerstone $1301 / 8 \mathrm{~m}$ ). All the electrochemical measurements were performed on an SP150 electrochemical workstation (SP-150, Bio-Logic SAS, France) at room temperature.

\section{Calculations}

The conversion between potentials $v s . \mathrm{Ag} / \mathrm{AgCl}$ and those $v s$. RHE is performed using the following equation [29]:

$$
\begin{gathered}
E(v s . \mathrm{RHE})=E(v s . \mathrm{Ag} / \mathrm{AgCl}) \\
+E_{\mathrm{Ag} / \mathrm{AgCl}}(\text { reference })+0.0591 \mathrm{~V} \times \mathrm{pH} \\
\left(E_{\mathrm{Ag} / \mathrm{AgCl}}(\text { reference })=0.1976 \mathrm{~V} v s . \mathrm{NHE} \text { at } 25^{\circ} \mathrm{C}\right) . \\
\mathrm{IPCE} \text { can be expressed as }[16]: \\
\text { IPCE }=(1240 \times I) /\left(\lambda \times J_{\text {light }}\right),
\end{gathered}
$$

where $I$ is the photocurrent density, $\lambda$ is the incident light wavelength, and $J_{\text {light }}$ is the measured irradiance. 

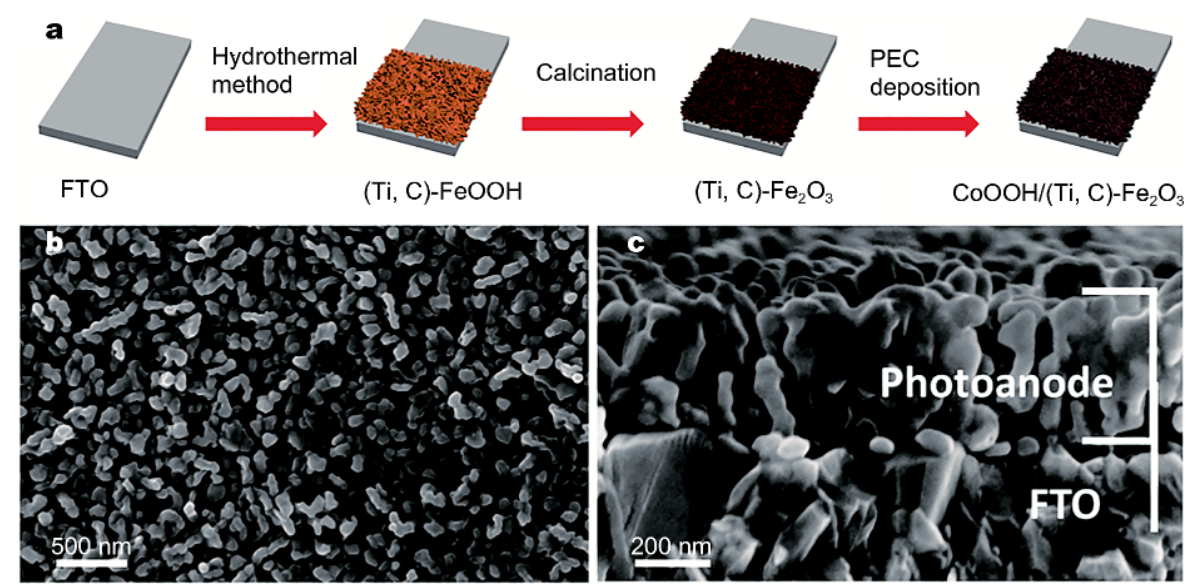

Figure 1 (a) Schematic diagrams for the growth of $\mathrm{CoOOH} /(\mathrm{Ti}, \mathrm{C})-\mathrm{Fe}_{2} \mathrm{O}_{3}$ nanorods photoanode. (b) Top-view and (c) side-view SEM images of $\mathrm{CoOOH} /(\mathrm{Ti}, \mathrm{C})-\mathrm{Fe}_{2} \mathrm{O}_{3}$ nanorods photoanode.

Yield of the surface reaching holes or the named transfer efficiency $\left(\Phi_{\text {OX }}\right)$ can be expressed as [29]:

$$
\Phi_{\mathrm{OX}}=J_{\mathrm{PEC}} / J_{\mathrm{HS}}
$$

where $J_{\mathrm{PEC}}$ is the practical water oxidation photocurrent and $J_{\mathrm{HS}}$ is the photocurrent density of sample with $\mathrm{Na}_{2} \mathrm{SO}_{3}$ hole scavenger.

Applied bias photo-to-current efficiency (ABPE) can be expressed as [12]:

$$
\mathrm{ABPE}=\left[J_{\mathrm{PEC}} \times\left(1.23-V_{\text {app }}\right)\right] / P_{\text {light }}
$$

where $J_{\mathrm{PEC}}$ is the photocurrent density of samples, $V_{\text {app }}$ is the applied external potential $v s$. RHE and $P_{\text {light }}$ is the power density of the illumination $\left(100 \mathrm{~mW} \mathrm{~cm}^{-2}\right)$.

\section{RESULTS AND DISCUSSION}

As shown in Fig. 1a, the $\mathrm{CoOOH} /(\mathrm{Ti}, \mathrm{C})-\mathrm{Fe}_{2} \mathrm{O}_{3}$ (CTCF) nanorods photoanode was synthesized on FTO glass substrate by three-step (Experimental section). Firstly, (Ti, C)-FeOOH nanorods film was synthesized hydrothermally. Then, the ( $\mathrm{Ti}, \mathrm{C})-\mathrm{FeOOH}$ nanorods film was transformed into ( $\mathrm{Ti}, \mathrm{C})-\mathrm{Fe}_{2} \mathrm{O}_{3}$ by calcination. Finally, the $\mathrm{CoOOH}$ as an oxygen evolution catalyst was deposited onto the (Ti, C) $-\mathrm{Fe}_{2} \mathrm{O}_{3}$ by a PEC deposition method.

The CTCF nanorods compactly grow on the FTO glass substrate with $400 \mathrm{~nm}$ long and $20 \mathrm{~nm}$ in diameter, as shown in the top-view SEM of CTCF (Fig. 1b) and the side-view SEM (Fig. 1c). XRD spectra were conducted to identify the crystalline phase of $\alpha-\mathrm{Fe}_{2} \mathrm{O}_{3}, \mathrm{C}-\mathrm{Fe}_{2} \mathrm{O}_{3},(\mathrm{Ti}, \mathrm{C})$ $\mathrm{Fe}_{2} \mathrm{O}_{3}$ (TCF) and CTCF, as shown in Fig. S2. Except the $\mathrm{SnO}_{2}$ peaks originating from the FTO substrate, all other diffraction peaks in the XRD spectra can be well indexed to $\alpha-\mathrm{Fe}_{2} \mathrm{O}_{3}$ (JCPDS 86-0550).

Diffuse reflectance UV-visible spectra of $\alpha-\mathrm{Fe}_{2} \mathrm{O}_{3}, \mathrm{C}$ $\mathrm{Fe}_{2} \mathrm{O}_{3}$, TCF and CTCF were collected to characterize the light harvesting capability and band gap. As shown in Fig. S3, the absorption edge of the as-synthesized samples are at $590 \mathrm{~nm}$, which is consistent with recent reports. The band gap of samples can be determined by the formula [30]:

$$
\alpha h v=A\left(h v-E_{\mathrm{g}}\right)^{n / 2},
$$

where $\alpha, h, v, A, E_{\mathrm{g}}$ and $n$ are absorption coefficient, Planck's constant, incident light frequency, proportionality constant, band-gap and characteristic integer, respectively. Among them, $n$ depends on the characteristics of the optical transition in a semiconductor, i.e., direct transition $(n=1)$ or indirect transition $(n=4)$ [23]. $\mathrm{Fe}_{2} \mathrm{O}_{3}$ pertains to indirect transition and the value of $n$ is 4 . As shown in Fig. S4, the absorption edges of the as-synthesized photoanodes are in the range of 590 to $600 \mathrm{~nm}$, respectively, and the band-gap energies of the samples are 1.9 to $2.0 \mathrm{eV}$, respectively, which are consistent with recent reports $[20,22,23]$.

Fig. S5 shows the XPS survey spectra of $\alpha-\mathrm{Fe}_{2} \mathrm{O}_{3},(\mathrm{Ti}$, C) $-\mathrm{Fe}_{2} \mathrm{O}_{3}$ and $\mathrm{CoOOH} /(\mathrm{Ti}, \mathrm{C})-\mathrm{Fe}_{2} \mathrm{O}_{3}$. Except the signals of $\mathrm{Sn}$ and $\mathrm{Si}$ from the FTO substrate and the $\mathrm{C}$ element from the adsorbed organics, only the signals of $\mathrm{Fe}$ and $\mathrm{O}$ elements can be detected. After adding glucose and $\mathrm{TiCl}_{3}$ and PEC deposition of $\mathrm{CoOOH}$, the obtained $\mathrm{CoOOH} /$ (Ti, C) $-\mathrm{Fe}_{2} \mathrm{O}_{3}$ nanorods show obvious XPS signals of $\mathrm{Ti}$ (Fig. S6a), demonstrating the successful doping of $\mathrm{Ti}$, and signals of $\mathrm{Fe}$ element origin from $\mathrm{Fe}_{2} \mathrm{O}_{3}$ (Fig. S6b), signals of $\mathrm{Co}$ origin from $\mathrm{CoOOH}$ (Fig. S6c), signals of $\mathrm{O}$ origin from $\mathrm{Fe}_{2} \mathrm{O}_{3}$ and $\mathrm{CoOOH}$ (Fig. S6d) [20,22,23,31].

TEM and high resolution TEM (HRTEM) were carried out to present the structure and morphology of the CTCF. The diameter of $\mathrm{Fe}_{2} \mathrm{O}_{3}$ nanorods is approximate $100 \mathrm{~nm}$ in agreement with the SEM result. The HRTEM 


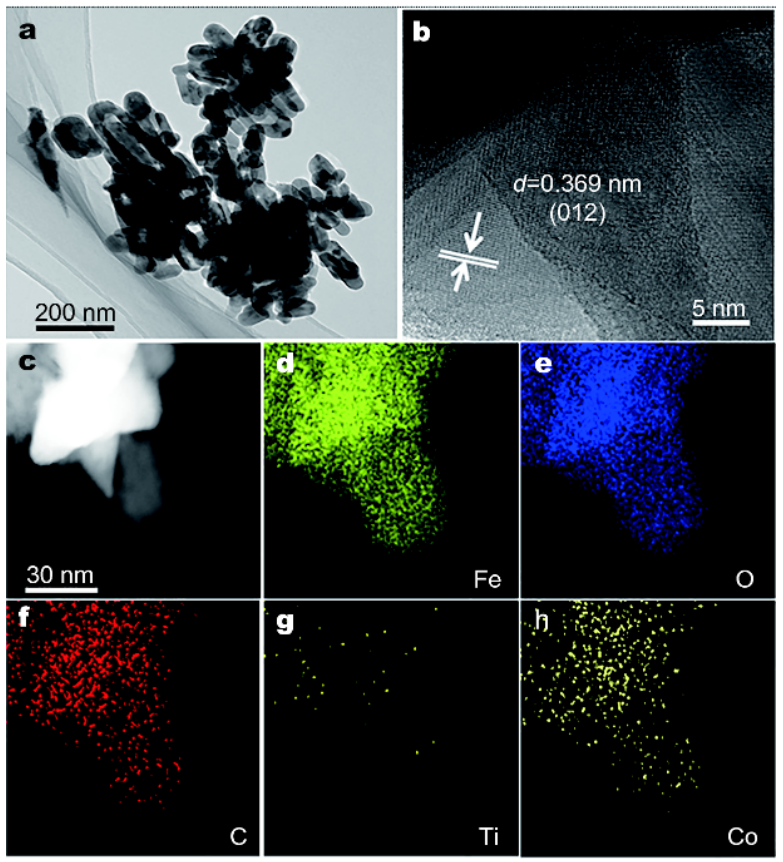

Figure 2 (a) TEM and (b) HRTEM images of the $\mathrm{CoOOH} /(\mathrm{Ti}, \mathrm{C})$ $\mathrm{Fe}_{2} \mathrm{O}_{3}$ nanorods. (c) HAADF-STEM image of the $\mathrm{CoOOH} /(\mathrm{Ti}, \mathrm{C})-\mathrm{Fe}_{2} \mathrm{O}_{3}$ nanorods, and $(\mathrm{d}-\mathrm{h})$ the corresponding STEM-EDS elemental mapping images of $\mathrm{Fe}, \mathrm{O}, \mathrm{C}, \mathrm{Ti}$ and $\mathrm{Co}$, respectively.

image (Fig. 2b) shows the spacing lattice fringes is about $0.369 \mathrm{~nm}$, corresponding to the (012) lattice planes of $\alpha$ $\mathrm{Fe}_{2} \mathrm{O}_{3}$, and in accordance with the XRD spectra. The results of TEM-energy dispersive spectrometer mapping (TEM-EDS) of CTCF nanorods reveal the homogeneous distribution of $\mathrm{Fe}, \mathrm{O}, \mathrm{C}, \mathrm{Ti}$ and $\mathrm{Co}$ in the whole selection area (Fig. 2c-h).

The systematic electrochemical and PEC performance of both the $\alpha-\mathrm{Fe}_{2} \mathrm{O}_{3}$ photoanode and the TCF photoanodes were characterized in $\left(0.5 \mathrm{~mol} \mathrm{~L}^{-1}\right), \mathrm{Na}_{2} \mathrm{SO}_{3}$ aqueous solution with $\mathrm{NaOH}$ solution $(\mathrm{pH} 14)$ as a hole scavenger, under AM 1.5G illumination. Fig. 3a compares the linear sweep voltammograms (LSV) curves of $\alpha-\mathrm{Fe}_{2} \mathrm{O}_{3}$ photoanode, $\mathrm{C}-\mathrm{Fe}_{2} \mathrm{O}_{3}$ photoanode, $\mathrm{Ti}-\alpha-\mathrm{Fe}_{2} \mathrm{O}_{3}$ photoanode and TCF photoanode. Even $J_{\max }$ of $\alpha-\mathrm{Fe}_{2} \mathrm{O}_{3}$ is more than $15 \mathrm{~mA} \mathrm{~cm}{ }^{-2}$, the photocurrent density of $\alpha-\mathrm{Fe}_{2} \mathrm{O}_{3}$ just only achieves $0.19 \mathrm{~mA} \mathrm{~cm}^{-2}$ at $+1.23 \mathrm{~V} v$ s. RHE, due to the poor electrical conductivity. However, after $\mathrm{C}$ and Ti doping, the TCF photoanode achieves a photocurrent density of $2.69 \mathrm{~mA} \mathrm{~cm}^{-2}$ at $+1.23 \mathrm{~V} v$ s. RHE, which is much higher than that of the $\alpha-\mathrm{Fe}_{2} \mathrm{O}_{3}$ photoanode $\left(0.19 \mathrm{~mA} \mathrm{~cm}^{-2}\right), \mathrm{C}^{-} \mathrm{Fe}_{2} \mathrm{O}_{3}$ photoanode $\left(0.80 \mathrm{~mA} \mathrm{~cm}{ }^{-2}\right)$ and Ti- $\mathrm{Fe}_{2} \mathrm{O}_{3}$ photoanode $\left(2.07 \mathrm{~mA} \mathrm{~cm}{ }^{-2}\right)$, because of the enhanced electrical conductivity due to the $\mathrm{C}$ and $\mathrm{Ti}$
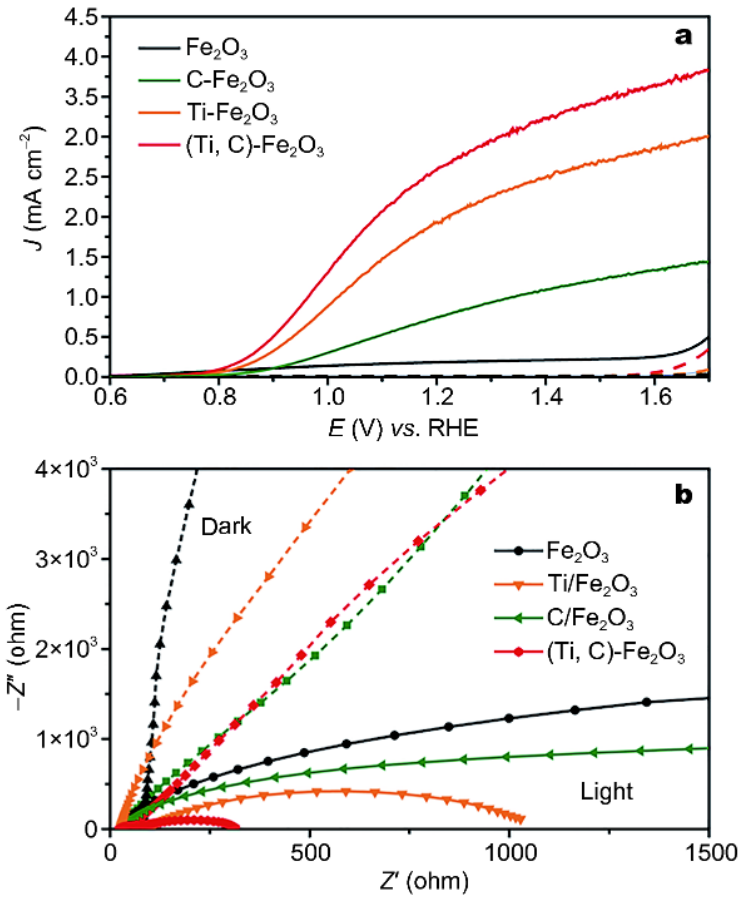

Figure 3 (a) LSV curves recorded at a scan rate of $25 \mathrm{mV} \mathrm{s}^{-1}$ under AM 1.5G irradiation in $\mathrm{Na}_{2} \mathrm{SO}_{3}$ electrolyte with $\mathrm{NaOH}$ as a hole scavenger (pH 14); (b) EIS Nyquist plots of the as-prepared samples.

doping in $\alpha-\mathrm{Fe}_{2} \mathrm{O}_{3}$ (Fig. 3b). Electrochemical impedance spectroscopy (EIS) were carried out to further investigate the relationship between doping and electrical conductivity. As shown in Fig. 3b, the arc radius of CTF photoanode both in the dark and under light is smaller than those of $\alpha-\mathrm{Fe}_{2} \mathrm{O}_{3}$ photoanode, $\mathrm{C}-\alpha-\mathrm{Fe}_{2} \mathrm{O}_{3}$ photoanode, and $\mathrm{Ti}-\alpha-\mathrm{Fe}_{2} \mathrm{O}_{3}$ photoanode in $\left(0.5 \mathrm{~mol} \mathrm{~L}^{-1}\right)$ $\mathrm{Na}_{2} \mathrm{SO}_{3}$ aqueous solution with $\mathrm{NaOH}$ solution ( $\mathrm{pH}$ 14) as a hole scavenger at $1.23 \mathrm{~V} v$ s. RHE. The results of EIS confirm the $\mathrm{C}$ and Ti doping can increase the electrical conductivity of $\alpha-\mathrm{Fe}_{2} \mathrm{O}_{3}$. Increasing the electrical conductivity of $\alpha-\mathrm{Fe}_{2} \mathrm{O}_{3}$ makes CTF photoanode achieve remarkable photocurrent density in solution with hole scavenger. Therefore, the $\mathrm{CoOOH}$ was used as OEC, which were deposited on the CFT photoanode surface by a PEC deposition method, to make maximum use of this photocurrent density of CTF in the solution without hole scavenger. In Fig. S7, the thickness of the $\mathrm{CoOOH}$ layer is about $5 \mathrm{~nm}$ and amorphous.

Fig. 4a compares the LSV curves of $\alpha-\mathrm{Fe}_{2} \mathrm{O}_{3}$ photoanode, $\mathrm{C}-\mathrm{Fe}_{2} \mathrm{O}_{3}$ photoanode, Ti- $\alpha-\mathrm{Fe}_{2} \mathrm{O}_{3}$ photoanode, TCF photoanode, and CTCF photoanode at a scan rate of $25 \mathrm{mV} \mathrm{s}^{-1}$ under the AM 1.5G irradiation. The CTCF photoanode achieves a photocurrent density of $1.85 \mathrm{~mA} \mathrm{~cm}^{-2}$ at $+1.23 \mathrm{~V} v$ s. RHE in the $\mathrm{NaOH}$ solution 

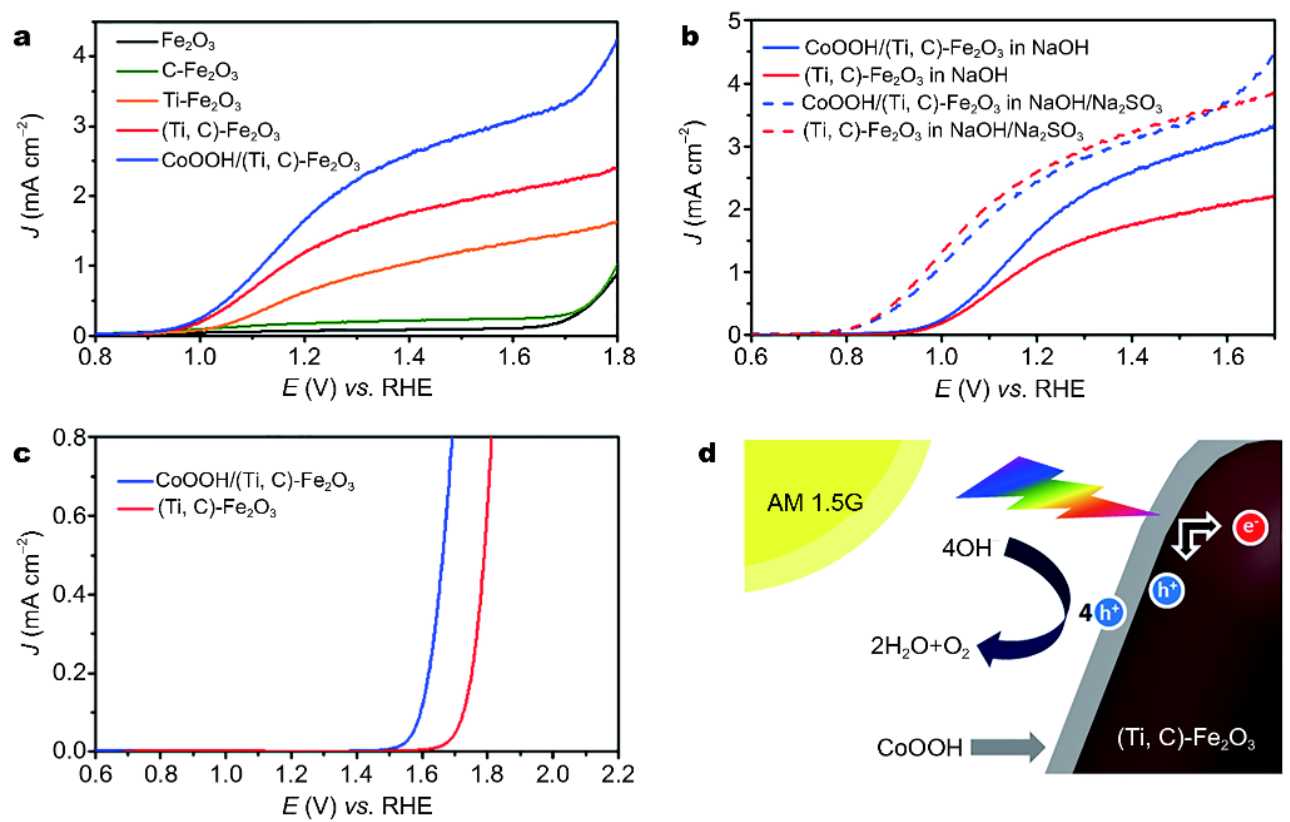

Figure 4 (a) LSV curves recorded at a scan rate of $25 \mathrm{mV} \mathrm{s}^{-1}$ under AM 1.5G irradiation in $\mathrm{NaOH}$ electrolyte (pH 14) with no hole scavenger and (b) with $\mathrm{Na}_{2} \mathrm{SO}_{3}$ as a hole scavenger. (c) LSV curves recorded at a scan rate of $25 \mathrm{mV} \mathrm{s}^{-1}$ in NaOH electrolyte (pH 14) with no hole scavenger under dark condition. (d) The illustration of PEC water oxidation at the CTCF photoanode.

without hole scavenger ( $\mathrm{pH} 14)$, which is much higher than that of the $\alpha-\mathrm{Fe}_{2} \mathrm{O}_{3}$ photoanode $\left(0.08 \mathrm{~mA} \mathrm{~cm}{ }^{-2}\right)$, C$\mathrm{Fe}_{2} \mathrm{O}_{3}$ photoanode $\left(0.18 \mathrm{~mA} \mathrm{~cm}{ }^{-2}\right)$, Ti- $\mathrm{Fe}_{2} \mathrm{O}_{3}$ photoanode $\left(0.71 \mathrm{~mA} \mathrm{~cm}^{-2}\right)$, TCF photoanode $\left(1.33 \mathrm{~mA} \mathrm{~cm}^{-2}\right)$. Due to the CoOOH OEC's effect, the CTCF photoanode achieves higher PEC water splitting performance than TCF photoanode, as illustrated in the LSV curves of TCF photoanode and CTCF photoanode in $\mathrm{NaOH}$ solution without hole scavenger and $\mathrm{NaOH}$ solution with $\mathrm{Na}_{2} \mathrm{SO}_{3}$ hole scavenger (Fig. 4b).

Since the oxidation rate of holes $\left(\Phi_{\mathrm{OX}}\right)$ on the electrolyte interface is very fast in the presence of $\mathrm{Na}_{2} \mathrm{SO}_{3}$ as hole scavenger, the surface recombination of charges is eliminated and $\Phi_{\mathrm{OX}} \approx 100 \%$. As shown in Fig. $4 \mathrm{~b}$, when $\mathrm{Na}_{2} \mathrm{SO}_{3}$ is added to the electrolyte, the photocurrents generated from CTCF photoanode and TCF photoanode under AM 1.5G illumination are $2.57 \mathrm{~mA} \mathrm{~cm}^{-2}$ and $2.69 \mathrm{~mA} \mathrm{~cm}^{-2}$ at $1.23 \mathrm{~V} v$ s. RHE, respectively. The $\Phi_{\mathrm{OX}}$ can be individually calculated using equation $\Phi_{\mathrm{OX}}=J_{\mathrm{PEC}} /$ $J_{\mathrm{HS}}$, and are plotted in Fig. S8. The $\Phi_{\mathrm{OX}}$ of CTCF photoanode $(68.2 \%,+1.23 \mathrm{~V}$ vs. RHE) is significantly higher than that of TCF $(46.1 \%)$ at $+1.23 \mathrm{~V}$ vs. RHE, which means that the improvement is from increasing holes OER capacity by $\mathrm{CoOOH}$ OEC. On the other hand, as shown in Fig. 4b, the CoOOH OEC not only can increase the OER capacity of photoanodes in the solution without hole scavenger, but also can enhance the photocurrent density of photoanode in the solution with $\mathrm{Na}_{2} \mathrm{SO}_{3}$ as hole scavenger, which means the $\mathrm{CoOOH}$ OEC will not reduce the charges separation of photoanodes.

Fig. 4c shows the LSV curves of CTCF photoanode and TCF photoanode in $\mathrm{NaOH}$ solution ( $\mathrm{pH}$ 14) without hole scavenger and illumination. The LSV curve of the CTCF photoanode generates a current density of $0.5 \mathrm{~mA} \mathrm{~cm}^{-2}$ at a potential of $+1.66 \mathrm{~V} v s$. RHE, which is much better than that of TCF photoanode $(+1.79 \mathrm{~V} v s$. RHE). These results verify that the $\mathrm{CoOOH}$ OEC can increase the OER capacity of photoanode in PEC water splitting.

The illustration of the PEC water oxidation at the CTCF photoanode is shown in Fig. 4d. When sun light radiates on the CTCF photoanode, the photo-generated electrons and holes are generated by $(\mathrm{Ti}, \mathrm{C})-\mathrm{Fe}_{2} \mathrm{O}_{3}$. In this process, due to the increased electrical conductivity of photoanode by $\mathrm{C}$ and $\mathrm{Ti}$ doping, the charges can transfer faster in photoanode. Then, photo-generated holes transfer to the $\mathrm{CoOOH}$ OEC layer by bias voltage and oxidize the $\mathrm{OH}^{-}$of solution on $\mathrm{CoOOH}$ layer surface. Therefore, the $\mathrm{C}$ and $\mathrm{Ti}$ in this PEC system can increase the photo-generated charges transport, and $\mathrm{CoOOH}$ OEC layer can increase the OER capacity as an OEC material.

The IPCE were further performed to investigate the PEC performances of $\alpha-\mathrm{Fe}_{2} \mathrm{O}_{3}$ photoanode, $\mathrm{Ti}-\mathrm{Fe}_{2} \mathrm{O}_{3}$ 
photoanode, TCF photoanode, and CTCF photoanode at $+1.23 \mathrm{~V}$ vs. $\mathrm{RHE}$ in $\mathrm{NaOH}$ solution ( $\mathrm{pH} 14)$. Fig. $5 \mathrm{a}$ shows the IPCE spectra of CTCF photoanode and TCF photoanode at $+1.23 \mathrm{~V} v s$. RHE, consistent with their current density-voltage $(J-V)$ characteristics. The maximum IPCE value of CTCF photoanode reaches $31.2 \%$ at $380 \mathrm{~nm}$, which is much higher than that of $\alpha-\mathrm{Fe}_{2} \mathrm{O}_{3}$ photoanode (2.2\%), $\mathrm{Ti}^{-} \mathrm{Fe}_{2} \mathrm{O}_{3}$ photoanode (16.1\%) and TCF photoanode (25.7\%). As shown in Fig. 5b, with the calculated ABPE as a function of external potential vs. RHE, the maximum efficiency for $\alpha-\mathrm{Fe}_{2} \mathrm{O}_{3}$ photoanode, $\mathrm{C}-\mathrm{Fe}_{2} \mathrm{O}_{3}$ photoanode, $\mathrm{Ti}-\mathrm{Fe}_{2} \mathrm{O}_{3}$ photoanode, TCF photoanode, and CTCF photoanode is $0.01 \%(0.99 \mathrm{~V} v s$. RHE), $0.02 \%(1.01 \mathrm{~V}$ vs. RHE), $0.04 \%$ ( $1.12 \mathrm{~V}$ vs. RHE), $0.08 \%$ $(1.08 \mathrm{~V}$ vs. RHE) and $0.11 \%(1.11 \mathrm{~V}$ vs. RHE), respectively. This result suggests that $\mathrm{C}$ and Ti doping and $\mathrm{CoOOH}$ OEC can increase PEC water splitting capacity of the $\alpha-\mathrm{Fe}_{2} \mathrm{O}_{3}$-based photoanode.

As shown in Fig. 6a and Movie S1, the CTCF photoanode exhibits excellent activity and operational stability for PEC water splitting in $\mathrm{NaOH}$ solution ( $\mathrm{pH}$ 14) at $1.23 \mathrm{~V} v$ s. RHE under AM 1.5G irradiation. The chronoamperometry $(i-t)$ curve of the CTCF photoanode was collected at $1.23 \mathrm{~V} v s$. RHE in $5 \mathrm{~h}$. The photocurrent of CTCF is initially about $1.84 \mathrm{~mA} \mathrm{~cm}^{-2}$ and decreases by $0.12 \mathrm{~mA} \mathrm{~cm}^{-2}$ within $5 \mathrm{~h}$, demonstrating that the CTCF photoanode is very stable during the long time irradiation at extreme voltage in $\mathrm{NaOH}$ ( $\mathrm{pH}$ 14). The SEM and XRD of the photoanode after stability test are shown in Fig. $S 9$ and S10. And there is no change in morphology and structure after $5 \mathrm{~h}$ reaction. These results confirm the high stability of the CTCF photoanode. Fig. $6 \mathrm{~b}$ is the photo image of CTCF photoanode PEC water splitting system, and Fig. $6 \mathrm{c}-\mathrm{e}$ are photo images of different parts of this system. We also tested the hydrogen generation rate at $1 \mathrm{~mA} \mathrm{~cm}^{-2}$ (Fig. S11). We find the generation rate of $\mathrm{H}_{2}$ by our PEC system is about $18.67 \mu \mathrm{mol} \mathrm{h}^{-1}$, with Faradic efficiency close to $99.89 \%$.

\section{CONCLUSIONS}

In summary, the CTCF photoanode was successfully prepared by hydrothermal, calcination and PEC deposition methods. XRD, SEM, TEM and XPS results confirmed the Ti and C were successfully doped in the $\mathrm{Fe}_{2} \mathrm{O}_{3}$, and the layered $\mathrm{CoOOH}$ OEC was on the surface of $(\mathrm{Ti}$, C) $-\mathrm{Fe}_{2} \mathrm{O}_{3}$. The CTCF photoanode shows significantly PEC water splitting capacity under sunlight (AM 1.5G). The photocurrent density of CTCF photoanode is $1.85 \mathrm{~mA} \mathrm{~cm}^{-2}$ at $+1.23 \mathrm{~V} v s$. RHE, which is more than 20 times higher than that of pristine $\alpha-\mathrm{Fe}_{2} \mathrm{O}_{3}$ photoanode
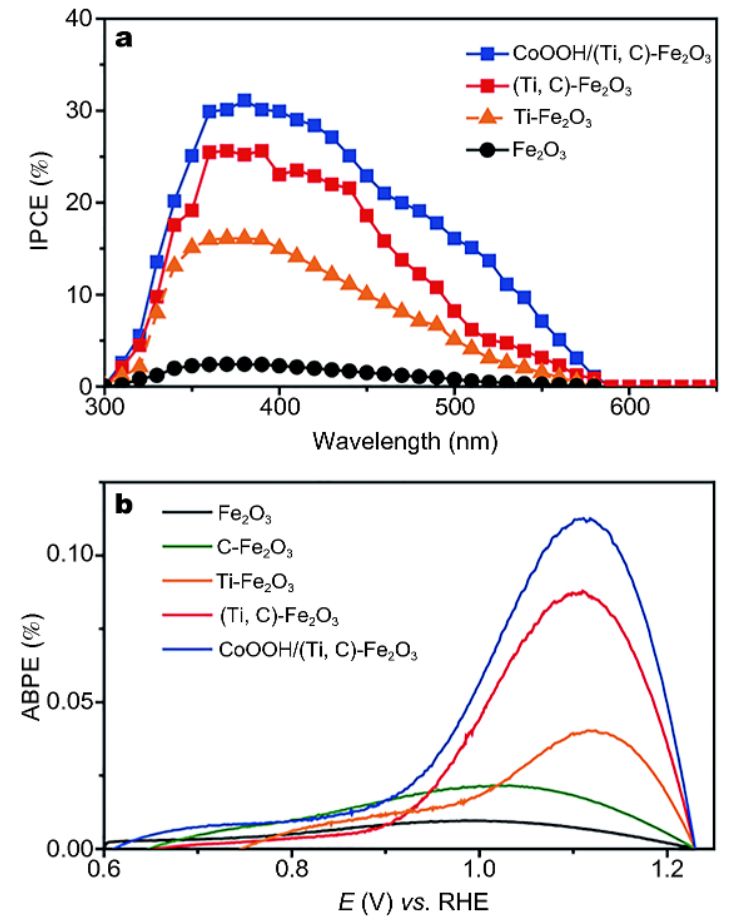

Figure 5 (a) IPCE and (b) ABPE spectra of the as-prepared photoanodes measured at bias $+1.23 \mathrm{~V} v$ s. RHE.

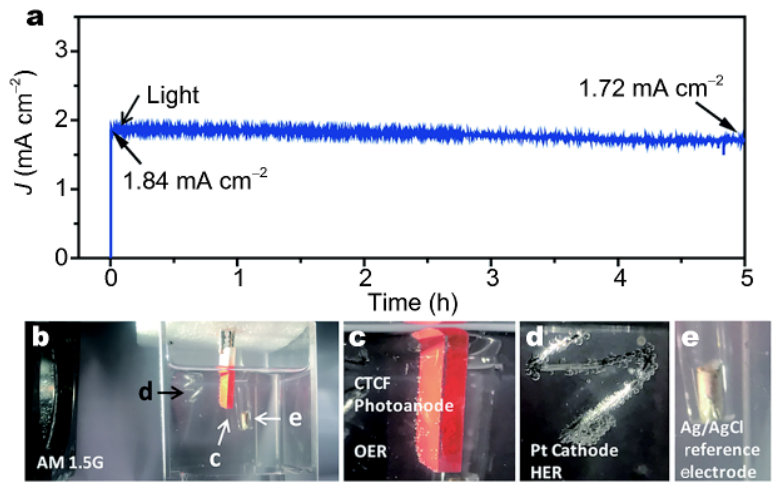

Figure 6 (a) Operational stability of the CTCF photoanode. Chronoamperometry $(i-t)$ curve of CTCF collected at $+1.23 \mathrm{~V} v s$. RHE under AM 1.5G illumination in $\mathrm{NaOH}$ electrolyte ( $\mathrm{pH}$ 14). Photo images of CTCF photoanode in PEC water splitting system (b), CTCF photoanode (c), Pt cathode (d) and $\mathrm{Ag} / \mathrm{AgCl}$ reference electrode (e).

$\left(0.08 \mathrm{~mA} \mathrm{~cm}^{-2}\right)$. The IPCE, ABPE and $\Phi_{\mathrm{OX}}$ of the CTCF photoanode reach $31.2 \%$ at $380 \mathrm{~nm}(+1.23 \mathrm{~V}$ vs. RHE), $0.11 \%(+1.11 \mathrm{~V} v s$. RHE), $68.2 \%(+1.23 \mathrm{~V} v s$. RHE), respectively, which are much higher than those of pristine $\alpha-\mathrm{Fe}_{2} \mathrm{O}_{3}$ photoanode. The long time irradiation PEC water splitting of CTCF photoanode demonstrates its high stability at extreme voltage in $\mathrm{NaOH}(\mathrm{pH}$ 14). These findings indicate the CTCF photoanode is a very pro- 
mising material for PEC water splitting.

\section{Received 29 October 2017; accepted 28 December 2017; published online 29 January 2018}

1 Grätzel M. Photoelectrochemical cells. Nature, 2001, 414: 338-344

2 Lu X, Xie S, Yang H, et al. Photoelectrochemical hydrogen production from biomass derivatives and water. Chem Soc Rev, 2014, 43: 7581-7593

3 Wang G, Yang Y, Ling Y, et al. An electrochemical method to enhance the performance of metal oxides for photoelectrochemical water oxidation. J Mater Chem A, 2016, 4: 2849-2855

4 Moniz S, Shevlin S, Martin D, et al. Visible-light driven heterojunction photocatalysts for water splitting-a critical review. Energy Environ Sci, 2015, 8: 731-759

5 Wang G, Yang Y, Han D, et al. Oxygen defective metal oxides for energy conversion and storage. Nano Today, 2017, 13: 23-39

6 Xie S, Zhai T, Li W, et al. Hydrogen production from solar driven glucose oxidation over $\mathrm{Ni}(\mathrm{OH})_{2}$ functionalized electroreduced$\mathrm{TiO}_{2}$ nanowire arrays. Green Chem, 2013, 15: 2434-2440

7 Xie S, Li M, Wei W, et al. Gold nanoparticles inducing surface disorders of titanium dioxide photoanode for efficient water splitting. Nano Energy, 2014, 10: 313-321

8 Mao Y, Yang H, Chen J, et al. Significant performance enhancement of $\mathrm{ZnO}$ photoanodes from $\mathrm{Ni}(\mathrm{OH})_{2}$ electrocatalyst nanosheets overcoating. Nano Energy, 2014, 6: 10-18

9 Wang G, Yang X, Qian F, et al. Double-sided CdS and CdSe quantum dot co-sensitized $\mathrm{ZnO}$ nanowire arrays for photoelectrochemical hydrogen generation. Nano Lett, 2010, 10: 1088-1092

10 Li M, He X, Zeng Y, et al. Solar-microbial hybrid device based on oxygen-deficient niobium pentoxide anodes for sustainable hydrogen production. Chem Sci, 2015, 6: 6799-6805

11 Ye K-, Chai Z, Gu J, et al. BiOI-BiVO 4 photoanodes with significantly improved solar water splitting capability: $\mathrm{p}-\mathrm{n}$ junction to expand solar adsorption range and facilitate charge carrier dynamics. Nano Energy, 2015, 18: 222-231

12 Ye K-, Wang Z, Gu J, et al. Carbon quantum dots as a visible light sensitizer to significantly increase the solar water splitting performance of bismuth vanadate photoanodes. Energy Environ Sci, 2017, 10: 772-779

13 Chen S, Zeng L, Tian $\mathrm{H}$, et al. Enhanced lattice oxygen reactivity over $\mathrm{Ni}$-modified $\mathrm{WO}_{3}$-based redox catalysts for chemical looping partial oxidation of methane. ACS Catal, 2017, 7: 3548-3559

14 Zhang J, Zhang P, Wang T, et al. Monoclinic $\mathrm{WO}_{3}$ nanomultilayers with preferentially exposed (002) facets for photoelectrochemical water splitting. Nano Energy, 2015, 11: 189-195

15 Li H, Zhao F, Zhang J, et al. A g- $\mathrm{C}_{3} \mathrm{~N}_{4} / \mathrm{WO}_{3}$ photoanode with exceptional ability for photoelectrochemical water splitting. Mater Chem Front, 2017, 1: 338-342

16 Li M, Yang Y, Ling Y, et al. Morphology and doping engineering of Sn-doped hematite nanowire photoanodes. Nano Lett, 2017, 17: 2490-2495

17 Zandi O, Hamann T. Determination of photoelectrochemical water oxidation intermediates on haematite electrode surfaces using operando infrared spectroscopy. Nat Chem, 2016, 8: 778-783

18 Shen S, Lindley S, Chen X, et al. Hematite heterostructures for photoelectrochemical water splitting: rational materials design and charge carrier dynamics. Energy Environ Sci, 2016, 9: 2744-2775

19 Kong B, Tang J, Selomulya C, et al. Oriented mesoporous nanopyramids as versatile plasmon-enhanced interfaces. J Am Chem

Soc, 2014, 136: 6822-6825

20 Qiu W, Huang Y, Long B, et al. Enhanced photoelectrochemical oxygen evolution reaction ability of iron-derived hematite photoanode with titanium modification. Chem Eur J, 2015, 21: 1925019256

21 Kim J, Youn D, Kang K, et al. Highly conformal deposition of an ultrathin $\mathrm{FeOOH}$ layer on a hematite nanostructure for efficient solar water splitting. Angew Chem, 2016, 128: 11012-11016

22 Gurudayal, Sabba D, Kumar M, et al. Perovskite-hematite tandem cells for efficient overall solar driven water splitting. Nano Lett, 2015, 15: 3833-3839

23 Luo Z, Wang $\mathrm{T}$, Zhang J, et al. Dendritic hematite nanoarray photoanode modified with a conformal titanium dioxide interlayer for effective charge collection. Angew Chem Int Ed, 2017, 56: $12878-12882$

24 Yuan Y, Gu J, Ye K-, et al. Combining bulk/surface engineering of hematite to synergistically improve its photoelectrochemical water splitting performance. ACS Appl Mater Interfaces, 2016, 8: 1607116077

25 Tang PY, Xie HB, Ros C, et al. Enhanced photoelectrochemical water splitting of hematite multilayer nanowire photoanodes by tuning the surface state via bottom-up interfacial engineering. Energy Environ Sci, 2017, 10: 2124-2136

26 Shi X, Choi I, Zhang K, et al. Efficient photoelectrochemical hydrogen production from bismuth vanadate-decorated tungsten trioxide helix nanostructures. Nat Commun, 2014, 5: 4775-4782

27 Bajdich M, García-Mota M, Vojvodic A, et al. Theoretical investigation of the activity of cobalt oxides for the electrochemical oxidation of water. J Am Chem Soc, 2013, 135: 13521-13530

28 Fu Z, Jiang T, Liu Z, et al. Highly photoactive Ti-doped $\alpha-\mathrm{Fe}_{2} \mathrm{O}_{3}$ nanorod arrays photoanode prepared by a hydrothermal method for photoelectrochemical water splitting. Electrochim Acta, 2014, 129: $358-363$

29 Kim T, Choi K-. Nanoporous $\mathrm{BiVO}_{4}$ photoanodes with dual-layer oxygen evolution catalysts for solar water splitting. Science, 2014, 343: 990-994

30 Huang $\mathrm{Y}, \mathrm{Hu} \mathrm{H}$, Wang $\mathrm{S}$, et al. Low concentration nitric acid facilitate rapid electron-hole separation in vacancy-rich bismuth oxyiodide for photo-thermo-synergistic oxidation of formaldehyde. Appl Catal B-Environ, 2017, 218: 700-708

31 Tao F, Zhao Y-, Zhang G-, et al. Electrochemical characterization on cobalt sulfide for electrochemical supercapacitors. Electrochem Commun, 2007, 9: 1282-1287

Acknowledgements This work was preliminarily supported by the National Natural Science Foundation of China (21706295, 51772135 and 21376104), the Natural Science Foundation of Guangdong Province (2017A030313055 and 2014A030306010) and Jinan University (11617326 and 88017418).

Author contributions Ye KH performed the main experiments; Wang $\mathrm{Z}$ and $\mathrm{Li} \mathrm{H}$ participated in the characterization; $\mathrm{Ye} \mathrm{KH}$ wrote the manuscript with support from Huang Y and Mai W. All authors contributed to the general discussion.

Conflict of interest The authors declare no conflict of interest.

Supplementary information online version of the paper.
Supporting data are available in the 

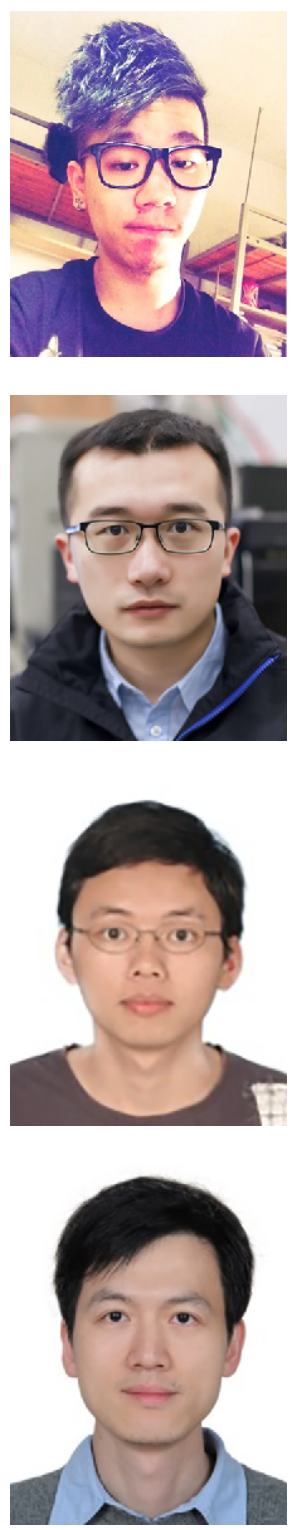

Kai-Hang Ye received his BSc degree in chemistry from Guangzhou University in 2014, MSc degree in physical chemistry from Jinan University (JNU) in 2017. Currently, he is a $\mathrm{PhD}$ student majored in physical chemistry from Sun Yat-Sen University (SYSU). His research interests include photoelectrochemical cell water splitting.

Zilong Wang received his BSc (2010) and MSc (2012) from the School of Chemistry and Chemical Engineering, SYSU. Then he received his PhD degree in Prof. Shihe Yang's group in Hong Kong University of Science and Technology. He is now a lecturer in JNU. His current research focuses on nanomaterials and their applications for energy storage and fuel cells.

Yongchao Huang received his BSc degree in chemistry from Huizhou University in 2011, MSc degree in chemistry from JNU in 2013, and PhD degree in chemistry from SYSU. Currently, he is an associate professor at the School of Environmental Science and Engineering, Guangzhou University. His research interests include environmental catalysis, such as photocatalysis and photoelectrochemical catalysis.

Wenjie Mai received his BSc degree in physics (2002) from Peking University (PKU) and PhD degree in materials science and engineering (2009) from Georgia Institute of Technology. He is now a Professor in JNU. His main research interest includes energy conversion, harvesting and storage devices, such as supercapacitors, dye-sensitised solar cells, nanogenerators, and photoelectrochemical water splitting.

\section{新型 $\mathrm{CoOOH} /(\mathrm{Ti}, \mathrm{C})-\mathrm{Fe}_{2} \mathrm{O}_{3}$ 纳米棒光阳极制备及其光电解水性能研究}

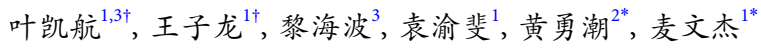

摘要 本论文利用一种温和的方法合成了 $\mathrm{CoOOH} /(\mathrm{Ti}, \mathrm{C})-\mathrm{Fe}_{2} \mathrm{O}_{3}$ (CTCF)纳米棒光阳极, 并对其光电解水性能进行了研究. 在可见光照和 $1.0 \mathrm{~V}$ 偏压(相对可逆氢电极)条件下, CTCF光阳极产生的光电流密度为 $1.85 \mathrm{~mA} \mathrm{~cm}$, 远高于传统的 $\alpha-\mathrm{Fe}_{2} \mathrm{O}_{3}$ 光阳极的光电流密度. 同时, 该 电极在强碱性电解液中 $(\mathrm{pH}$ 14)可以保持较长时间的稳定性. 